\title{
USE OF CUSTOMER SATISFACTION SURVEY IN ANALYTICAL MARKETING OF A RESEARCH INSTITUTE
}

\author{
Mateusz DULEWSKI ${ }^{1 *}$, Izabela JONEK-KOWALSKA ${ }^{2}$ \\ 1*Central Mining Institute, Poland; mateusz@dulewski.pl, ORCID: 0000-0001-9169-9918 \\ ${ }^{2}$ Silesian University of Technology, Faculty of Organization and Management, Poland; \\ izabela.jonek-kowalska@polsl.pl, ORCID: 0000-0002-4006-4362 \\ * Correspondence author
}

Purpose: Research institutes in Poland, when focusing on scientific and research activities, do not always find time and are not always keen on preparing and using modern marketing tools. Meanwhile, these tools in the conditions of strong competition could significantly improve their relations with customers and the strength of market influence. Given the above circumstances, the purpose of this article is to present the design, implementation and results of a customer satisfaction survey at one of the Polish research institutes.

Design/methodology/approach: As part of the design and implementation of the customer satisfaction survey, the Net Promoter Score method and marketing automation instruments were used to assess the quality of customer relations and the level of customer loyalty to the studied institute (case study).

Findings: The surveyed customers were mostly satisfied with the services and relationships with the described research institute. The areas requiring improvement were the pricing policy and the way the offer was presented.

Research limitations/implications: Limitations resulting from research are typical for case studies and relate to the inability to generalize the results. Nevertheless, the obtained conclusions may constitute the basis for improving analytical marketing tools in other research units.

Originality/value: The cognitive value of the article includes the design and implementation of a customer satisfaction survey at a research institute, and personalized practical conclusions about the level of customer satisfaction and loyalty of the studied institute.

Keywords: analytical marketing; research institute; customer satisfaction survey; customer relations; customer loyalty.

Category of the paper: research article. 


\section{Introduction}

The traditional rules of operation have changed significantly in modern marketing. Managers' intuition and experience are crowded out by techniques for collecting, processing and interpreting user data about their characteristics and behavior patterns. This data is directly obtained from Internet networks and is often supported by data on the users' geolocation, which enables the precise location of potential recipients (Lytras et al., 2020).

The trend described above has changed many aspects of marketing, including among others: media purchase (implementation of the automatic ordering model for advertising space), customer relations management (precise segmentation of target groups) and creation of messages to specific target groups in real time (France et al., 2019; Banach, 2017).

What counts in advertising today is not only the context of the content (pages viewed/read by Internet users), but also the context of the user - who they are, what they are like, what they like, what they buy on the Internet, what they did and are doing online now.

Managers mainly use their own and external data. Combining both groups of data allows to get a richer picture of individual customer segments, taking into account their traits, behaviors, content consumption methods and shopping habits. It is a great tool to reach users with the highest marketing value (Banach, 2016).

Advertisers widely use the data indicated above, both in efficiency, reach and image building campaigns. The main purpose of the campaign using data is to acquire leads and generate online sales. Advertisers in effect-oriented campaigns willingly use their own data in retargeting ${ }^{1}$, with an advertisement reaching the users who have already visited their website or online store but have not converted (Cao et al., 2019). On the other hand, among external data for efficiency activities managers mainly use:

- shopping intentions, i.e. what products the user added to the basket but did not make the purchase,

- precise interest profiles, i.e. what topics the user has intensively searched for content and read on the Internet,

- geolocation, i.e. where they physically were or are at a given moment,

- look-alike, i.e. data that allows you to find and reach with an advertisement users on the Internet similar to those who visited the advertiser's website or did shopping on it.

On the other hand, in branding campaigns ${ }^{2}$ (building an image) managers base such campaigns on the interests of customers and demographic data (age, gender). Relatively, they use professional profiles (position / profession, industry) the least (Żulicki, 2019).

\footnotetext{
${ }^{1}$ Retargeting (or remarketing) is a form of Internet advertising consisting in reaching with an advertising message, Internet users who have already visited the entity's website.

${ }^{2}$ Branding comes down to activities that aim to like us, our company or our products and to connect us, our company and our products, with the associations we care about. Typical branding often comes down to building brand awareness, i.e. we do everything to let customers know who we are.
} 
By using a marketing based on data approach in conjunction with developing technological possibilities, in real time at individual stages of the purchasing path you can already direct a unique advertising message to a single customer tailored to the stage in their decision path and consistent with their previous choices (Yu et al., 2019).

The goal of marketing based on data, i.e. analytical marketing, is to optimize processes and marketing communication in order to draw conclusions to better understand the customer and their current needs by combining data from various sources and then analyzing them (Wang, and Wang, 2020).

Learning the answers to the questions: 'who?', 'What?', 'When?', 'Where?' and 'why?' you can not only run problem free and effective, but above all successful online campaigns, allowing you to reach a personalized user with a message, which in turn translates into increased sales (Kakatkar, and Spann, 2019).

One of the tools used to collect data for analytical marketing is the customer satisfaction survey. Online customer reviews are currently one of the most powerful tools of modern managers who are responsible for promoting products and services. In 2017, 95\% of consumers read online reviews before making a purchase decision, and $85 \%$ trusted online reviews as much as personal recommendations (Mondry, 2017). Therefore, customer reviews, both good and bad, are a lever for business, build a brand and distinguish it from the competition. With the development of electronic media marketing, consumers have become better informed and empowered than ever before, therefore, in order to fully utilize the power of reviews to strengthen your brand, you should take what customers say about the product or service very seriously (Misirlis, and Vlachopoulou, 2019).

The use of data marketing is now common in the business sphere, which quickly adopts and uses management innovations. The sphere of science in Poland is often devoid of modern marketing tools, which makes it difficult for it to cope with competition on the free market. Meanwhile, the task of 219 research institutes is to support R\&D activities and to offer, on a commercial basis, the latest technological solutions for the Polish economy. Given the above circumstances, the purpose of this article is to present the design, implementation and results of a customer satisfaction survey at one of the Polish research institutes.

To achieve this posed goal, the research methodology used and the results of the research covering two threads are presented below. The first is the assessment of the customer loyalty of the studied institute, and the second is the assessment of the level of satisfaction with the services offered by the unit. At the end, areas of customer relations that need improvement were identified and the results of both marketing surveys were summarized. 


\section{Methodology}

Data marketing research was carried out in two stages. The first assessed the quality of services rendered by the institute using the questionnaire presented below (Figure 1).

\section{HOW DO YOU ASSESS OUR COMMITMENT}

1. How did you find out about our services:

- Google search,

- a recommendation,

- I am already your customer,

- fairs and conferences,

- consumer advertising (banner, billboard, radio, TV, leaflet),

- social media (Facebook, Youtube),

- other.

2. Assessment of the manner of cooperation and communication at the stage of processing orders:

- very good,

- good,

- satisfactory,

- unsatisfactory.

3. The price for the service is:

- too high and unacceptable,

- high but acceptable,

- very competitive,

- too low and may mean poor quality.

4. Is the offer presented readable and does it fully answer your inquiry?

- yes,

- no.

5. Will you recommend our services?

- yes,

- no.

6. Your opinion is essential for us:

Figure 1. Survey questionnaire for testing the quality of services at the studied research institute. Source: own work.

The survey is short but it provides relevant information on the channels of communication with the customer upon first contact, the proposed price and how to prepare and present the offer. The institute can also assess the marketing effect of first contact by asking about the possibility of further recommending its offer. The survey also included one open question, giving the customer a freedom of expression, and the opportunity to obtain information beyond the scope of the survey for the institute. Wanting to know the opinions of potential institute customers, one of the marketing automation tools was used, a survey of customer service quality and customer satisfaction was initiated, along with loyalty measurement for each potential customer who submitted an inquiry via the contact form. 
The second stage of the research was of a deepened nature, and its task was to assess the degree of satisfaction with the services of the research institute. At this stage, the Net Promoter Score (NPS) method was used, in which the customer decides on an eleven-point scale, whether they would recommend a given service to another recipient (Figure 2).

\begin{tabular}{|c|c|c|c|c|c|c|c|c|c|c|}
\hline 0 & 1 & 2 & 3 & 4 & 5 & 6 & 7 & 8 & 9 & 10 \\
\hline $\begin{array}{l}\text { I will not } \\
\text { recommend }\end{array}$ & & & & & & & & & & $\begin{array}{c}\text { I will } \\
\text { definitely } \\
\text { recommend }\end{array}$ \\
\hline
\end{tabular}

Figure 2. Net Promoter Score (NPS): Would you recommend our service/product to another customer? Source: https://www.webankieta.pl/badania-klientow/net-promoter-score.

The results obtained by way of the described surveys were used to assess the degree of customer satisfaction and loyalty of the studied institute. They also helped to identify the weaknesses of the institute's offer and implement appropriate remedial actions.

\section{Research results}

\subsection{Assessment of service quality as well as customer satisfaction and loyalty}

44 customers of the studied institute took part in the first survey. $45 \%$ of respondents are regular customers who have used the services of this entity again. The remaining part of the respondents is a new group of potential recipients (Figure 3). $27 \%$ of all respondents found out about the institute's offer via the Internet, which clearly exposes the importance of electronic media in the modern market of scientific and research services. $14 \%$ of the group are customers who have been recommended to use the institute's services. Definitely fewer recipients found out about the institute's offer from social media, consumer ads or other means of relaying marketing communication. So despite the huge popularity, social media and traditional advertising are not an effective promotion tool for research institutes. 


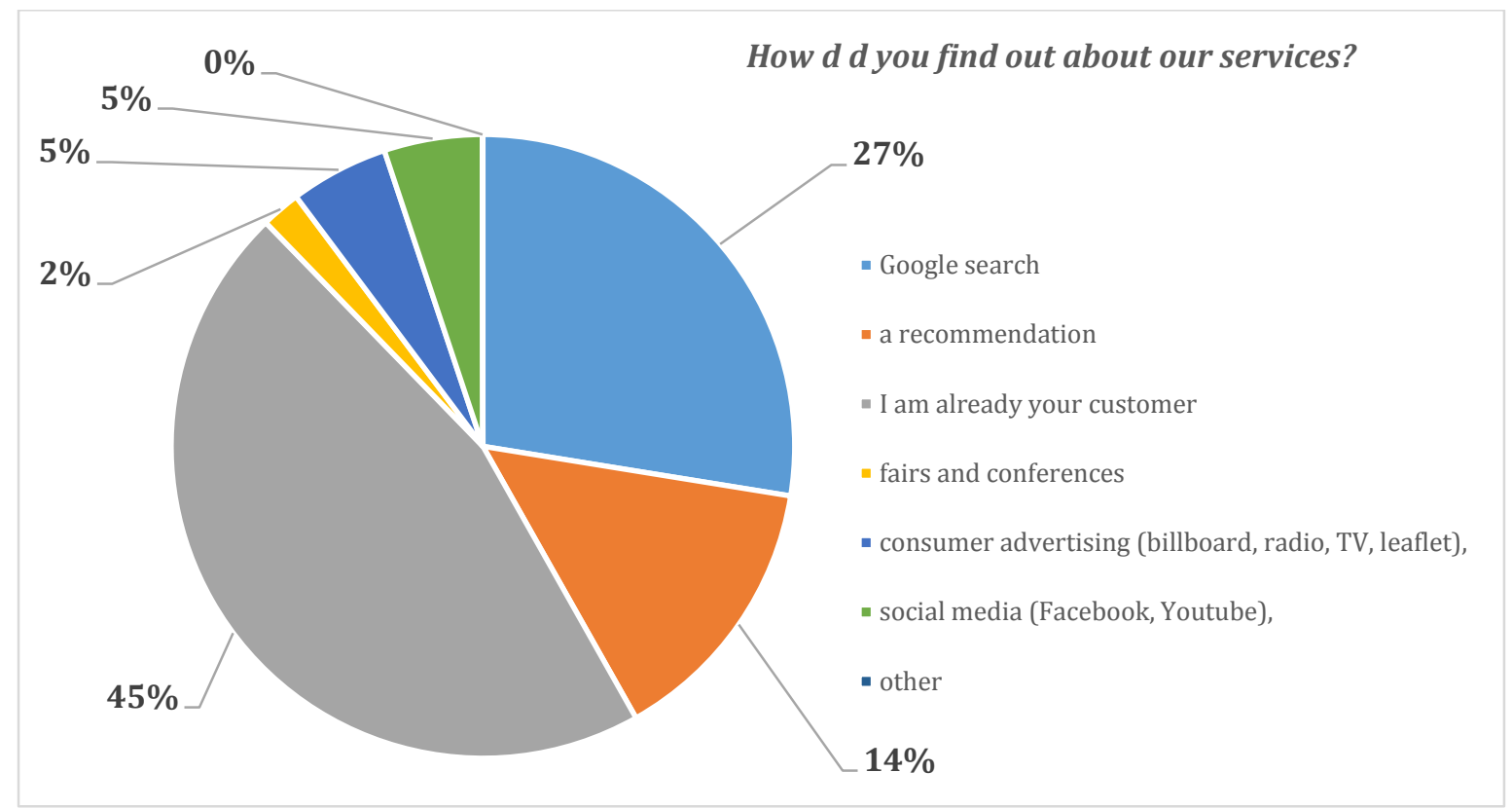

Figure 3. Distribution of answers to the questions: How did you find out about our services? Source: own elaboration based on questionnaire surveys.

\section{Asses ment of the manner of cooperation and communication at the stage of processing orders}

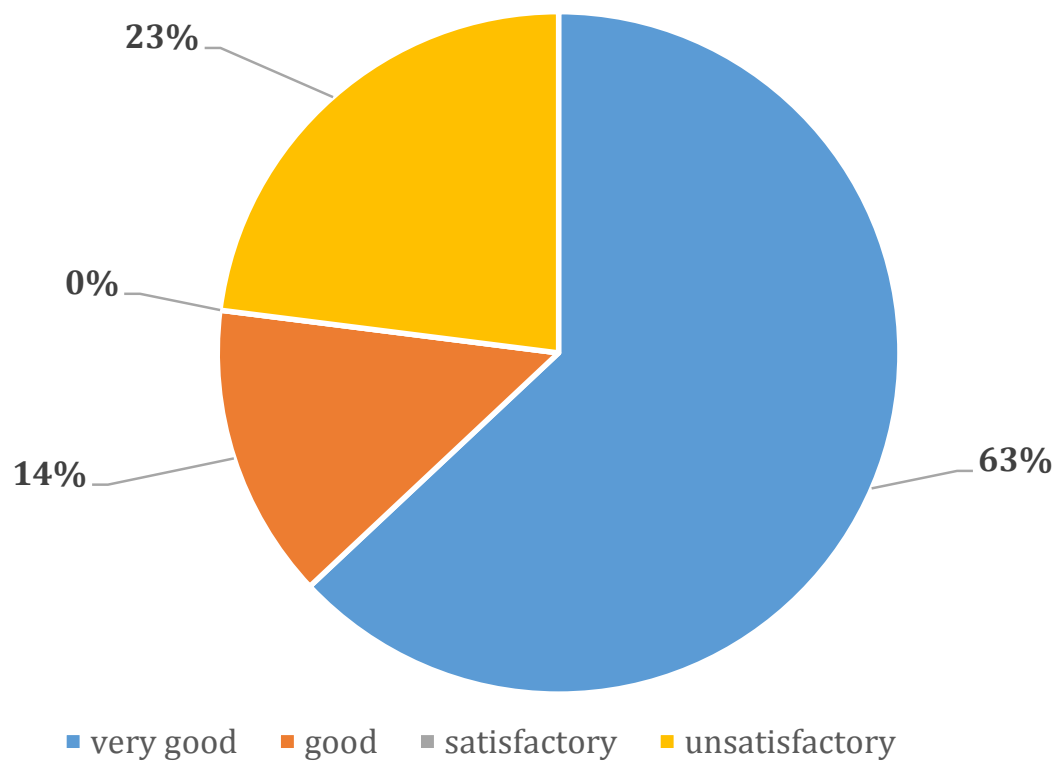

Figure 4. Distribution of answers to the questions: Assessment of the manner of cooperation and communication at the stage of processing orders. Source: own elaboration based on questionnaire surveys.

The studied institute received a lot of good and very good ratings in cooperation and communication functioning at the stage of the processing of orders (Figure 4 ) $-77 \%$ of responses. Unfortunately, at the same time, as many as $23 \%$ of respondents gave the institute an unsatisfactory rating in this category. At this point, it should be clarified that the implementation of services by the institute is very individualized, the conclusion of contracts is 
not standard and wholesale, therefore the reasons for customer dissatisfaction should be looked at in a particular way. And so, the negative reviews of potential institute customers most often concerned too long a waiting period for the offer or the lack of immediate contact with the customer, which, given the limited number of orders and customers, can be treated as a serious irregularity in relations with recipients.

The next question concerned the proposed price. For 55\% of respondents it was high but acceptable (Figure 5). However, as many as $27 \%$ considered it too high and unacceptable, only less than $1 / 5$ considered it competitive. Such ratings mean that most potential customers give up on further negotiations and concluding a contract, and look for the possibility of a cheaper way to meet service needs. This situation is also the result of current market conditions, in which the competitive position of the institute has definitely weakened and the market of potential customers has shrunk considerably.

The p ice for implementation is:

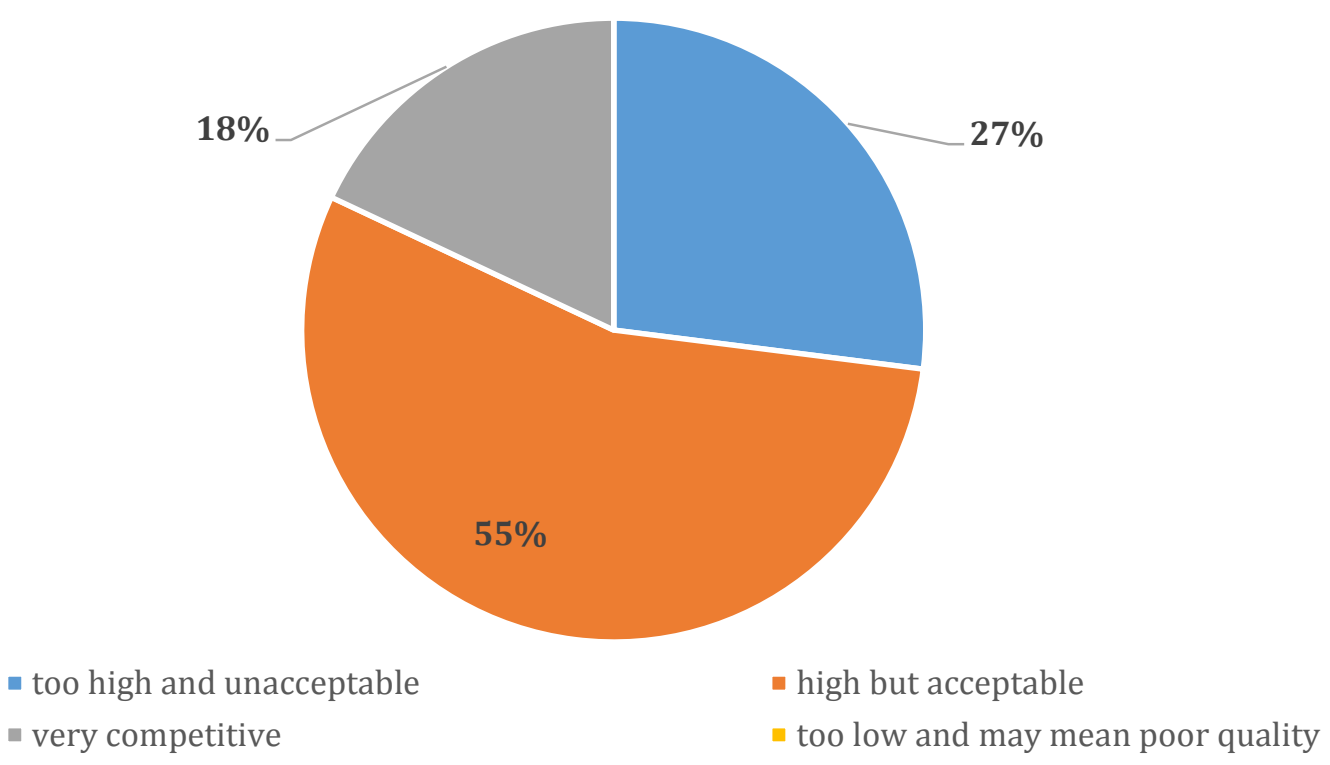

Figure 5. Distribution of answers to the question on the presented offer price. Source: own elaboration based on questionnaire surveys.

The way the offer is presented in terms of readability and sufficiency also needs to be improved, as over $1 / 3$ of respondents have assessed these criteria negatively, which may also discourage them from deepening contacts and concluding a contract (Figure 6). 
Is th offer presented readable and does it fully answer your inquiry?

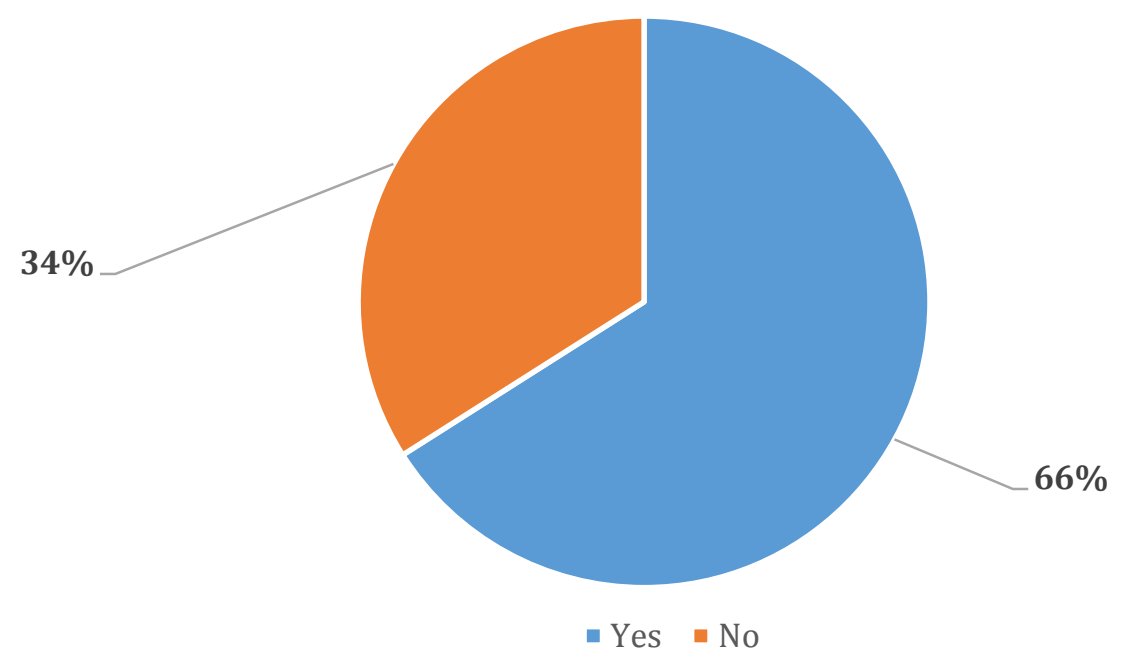

Figure 6. Distribution of answers to the questions: Is the offer presented readable and does it fully answer your inquiry? Source: own elaboration based on questionnaire surveys.

As a result of the negative perception of the price and the manner of presenting the offer, as well as delays in contact and cooperation, $25 \%$ of respondents would not recommend the services of the institute, which means (Figure 7) that as many as 11 out of 44 respondents would resign from the services of the institute and would most likely become a source of negative PR for this entity. In the context of a decreasing group of recipients and growing competition, such results may contribute to a significant deterioration in the competitiveness of the studied institute.

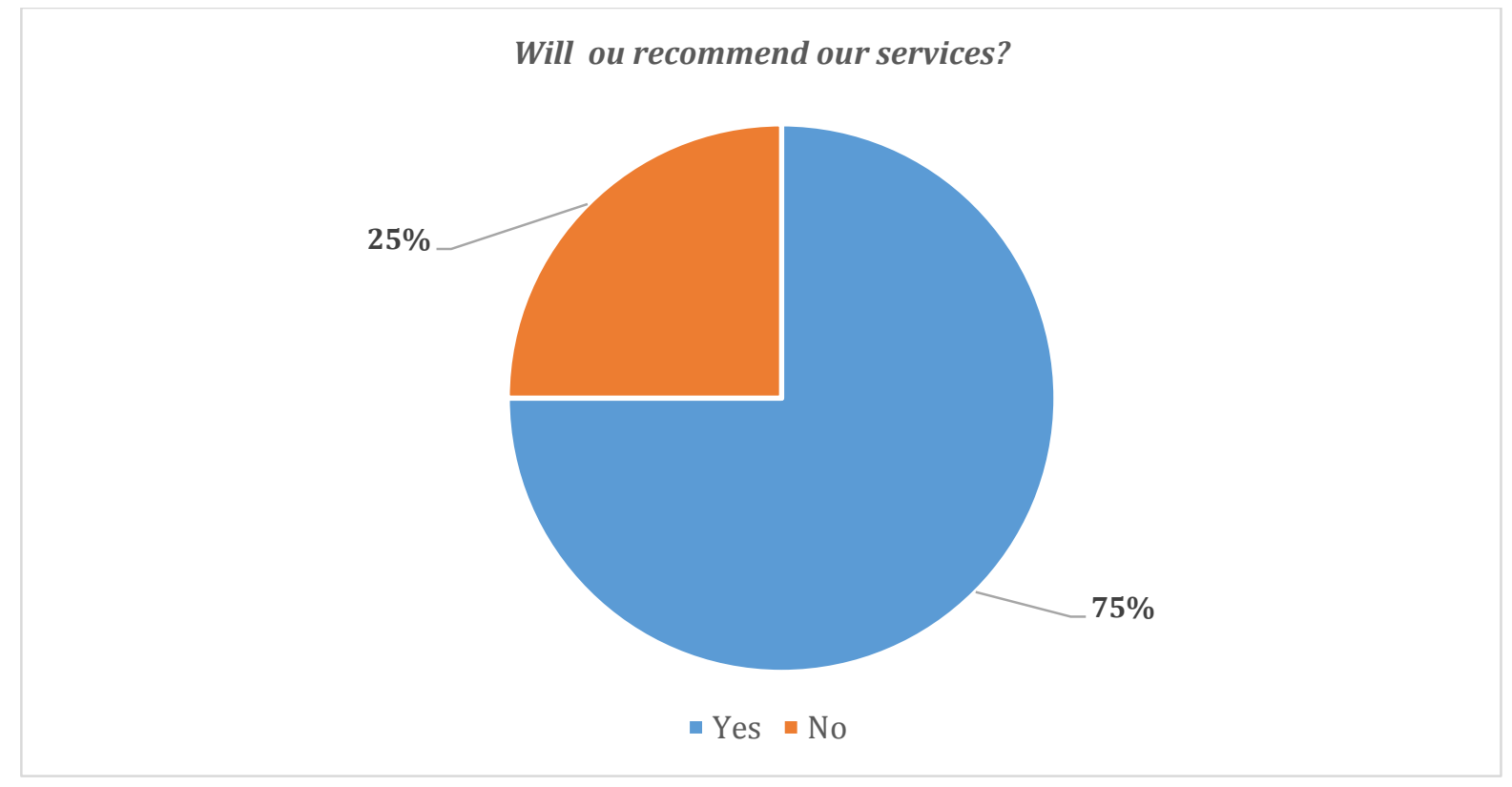

Figure 7. Distribution of answers to the questions: Will you recommend our services? Source: own elaboration based on questionnaire surveys. 
In the further part of the research, the assessment of customer satisfaction and their loyalty was deepened using the NPS method. This time, 72 customers took part in the survey, which were obtained as part of marketing activities in the period from January 2017 to September 2019 , and they were the only customers who decided to cooperate with the unit. The results are presented in Figure 8.

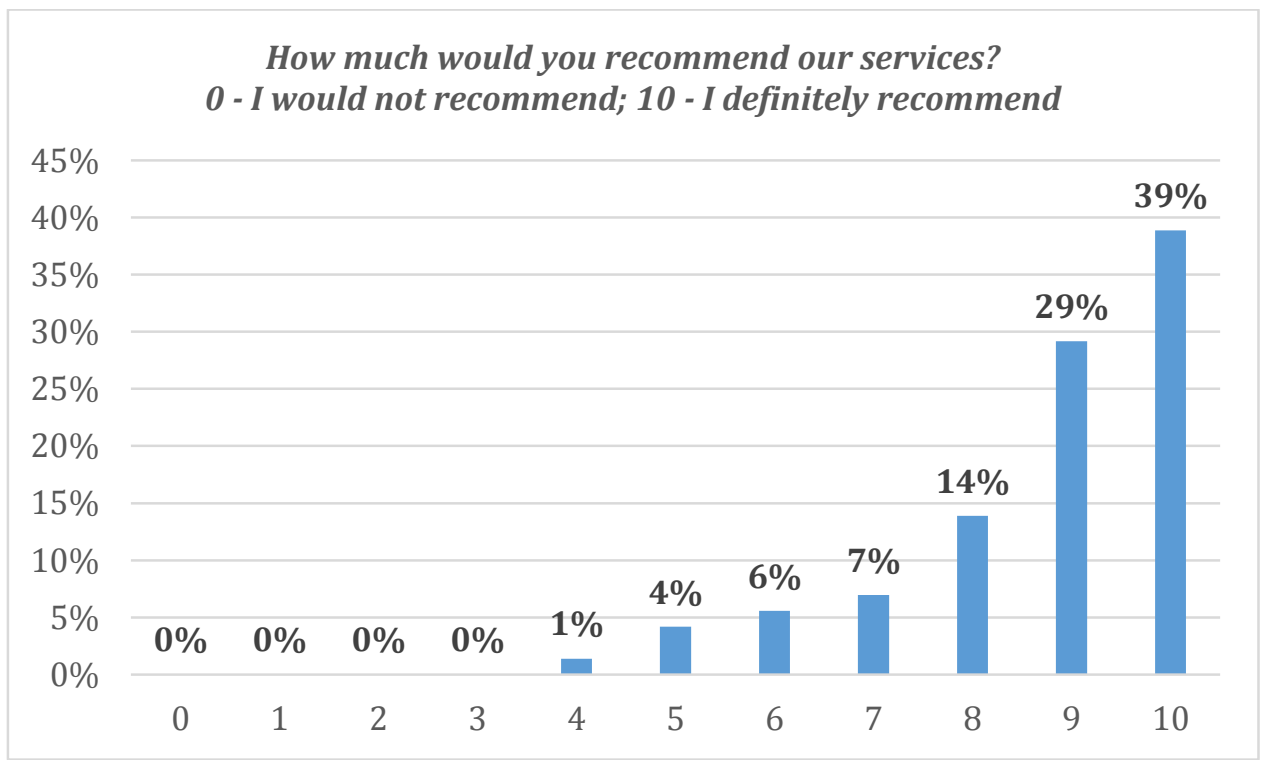

Figure 8. Distribution of answers in the Net Promoter Score (NPS). Source: own study based on surveys and iPresso.

A significant proportion of customers were satisfied with the institute's cooperation and would recommend its services to other entities (68\% of ratings were 9 and 10$)$. In addition, none of the ratings were below 4 points. This means that the institute's customers are mainly so-called promoters (ratings of 9-10) who can speak very well about the institute, recommend its offer and use its services more and more often than others. They also forgive stumbling blocks and enthusiastically help develop the institute's products and services. A smaller group of customers are so-called neutral (ratings of 7-8) who will not recommend services, and neither do black PR. In the case of a cheaper offer, these customers will move to the competition because they are more price sensitive. About $11 \%$ of respondents are so-called critics (ratings of 0-6). They are weakly connected with the institute, they quickly resign from its services and are a source of bad PR. Therefore, in the described scope, one should mainly focus on better service for those respondents who rated the cooperation with the institute the lowest and on maintaining the current good customer service.

\subsection{Actions improving cooperation with customers based on the results obtained using data marketing}

Based on the first part of the research, interviews were conducted with research staff responsible for developing surveys and contact with customers. As a result of consultations, it turned out that these people were not aware of the existing problems. Therefore, data obtained 
as part of marketing contributed to the awareness of the need to improve offers in terms of price, time and communication.

As part of remedial actions (in addition to internal work on improving the handling of offers), the surveyed customers received a reply to the survey comments sent. Responding to reviews is an important step in the scope of building trust among customers. A reliable, well-written response from an employee can humanize the brand $-52 \%$ of customers expect a response from the brand within seven days of writing an online review - both those negative and positive.

While it is easy to view and respond to positive reviews, it is difficult to critically approach the negatives. There are a few general tips to keep in mind, regardless of whether the review is positive or negative. The first assumes that contact should be fast. It is also important who responds to the comments. The higher the position in the hierarchy, the more seriously the reply is perceived. The reply should also directly refer to the customer's comments, only then may they feel respected, and this will increase their loyalty to the institute. Customers leaving negative reviews want to be heard and want their problem to be resolved.

The designed and implemented system of responses to reviews at the surveyed research institute is presented in Figure 9.

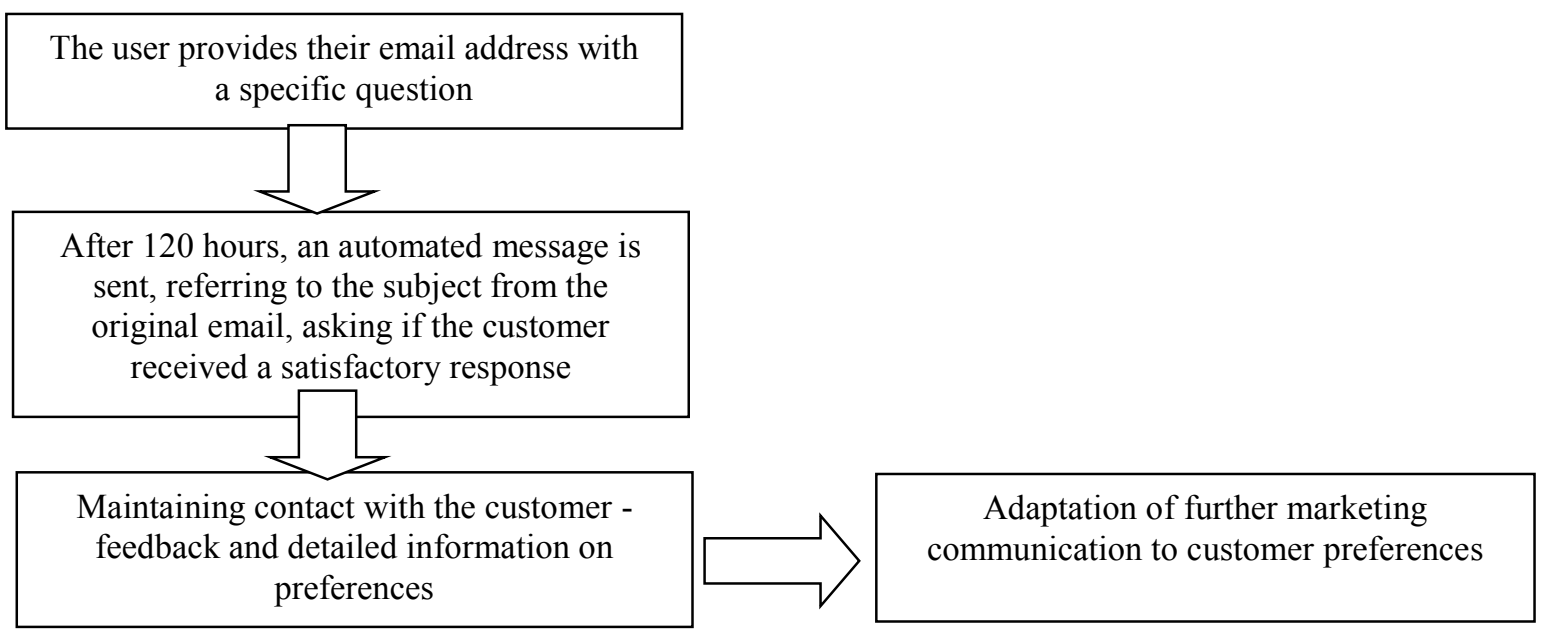

Figure 9. Algorithm of continuity of email communication. Source: own study based on surveys and iPresso.

Customers who were included in the feedback system were positively surprised by the institute's interest and responded positively to the implemented procedures. In addition to formal activities, the institute also revised its pricing policy and pointed out the need to eliminate communication delays and to specify clear and readable offers. All these activities are aimed at improving customer relations and, as a result, increasing the number of transactions and the value of sales revenues. 


\section{Conclusions}

As part of data marketing, two instruments for assessing customer satisfaction and loyalty were designed and implemented in the studied institute. The first of these referred to the initial contact phase of the customer and the institute and took the form of a short survey on methods of handling it. This survey is carried out using so-called marketing automation. The second instrument is a Net Promoter Score (NPS) survey that helps identify the strength of the customer's relationship with the institute.

The results of the research carried out using the above mentioned tools helped to claim that a large group of potential and current customers of the institute are satisfied with both the initial contact and service, as well as the final implementation of the order. Nevertheless, about a $1 / 4$ of potential customers do not enter into contracts with the institute due to too high prices, delays in contact and a vaguely readable offer. There is also a $11 \%$ group of former customers who would not recommend the institute's services to other entities (so-called critics). These groups require special care and attention, because disseminating their opinion may threaten the image of the institute and its competitive position. In this regard, remedial actions have already been taken to improve initial service, reduce prices and maintain constant and full contact with the customer.

\section{Acknowledgments}

This paper was financed from the resources of the Silesian University of Technology, project no. BK-235/ROZ-1/2020 (13/010/BK_20/0042).

\section{References}

1. Banach, A. (2017). Marketing oparty na danych buduje sprzedaż, zasięg i wizerunek. Sprawny Marketing, 6.

2. Banach, A. (2016). Data-Driven Marketing w Polsce. Marketing danych. Executive summary. Netsprint Group.

3. Cao, G., Duan, Y., Banna, A.E. (2019). A dynamic capability view of marketing analytics: Evidence from UK firms. Industrial Marketing Management, 76, 72-83.

4. France, S.L., Ghose, S. (2019). Marketing analytics: Methods, practice, implementation, and links to other fields. Expert Systems with Applications, 1191, 456-475. 
5. https://www.webankieta.pl/badania-klientow/net-promoter-score.

6. Kakatkar, Ch., Spann, M. (2019). Marketing analytics using anonymized and fragmented tracking data. International Journal of Research in Marketing, 36(1), 117-136.

7. Lytras, M., Visvizi, A., Zhang, X., Aljohani, N. R. (2020). Cognitive computing, Big Data Analytics and data driven industrial marketing. Industrial Marketing Management. In press. Available online 2 April 2020.

8. Misirlis, N., Vlachopoulou, M. (2019). Social media metrics and analytics in marketing S3M: A mapping literature review. International Journal of Information Management, 38, 270-276.

9. Mondry, A. (2017). Bluerank i Rainbow - kampanie reklamowe napędzane danymi. Online Marketing Magazyn, 3(34).

10. Wang, W.Y.Ch., Wang, Y. (2020). Analytics in the era of big data: The digital transformations and value creation in industrial marketing. Industrial Marketing Management, 86, 12-15.

11. Yu, Ch., Zhang, Z., Lin, Ch., Wu, Y.J. (2019). Can data-driven precision marketing promote user ad clicks? Evidence from advertising in WeChat moments. Industrial Marketing Management. In press. Available online 22 May 2019.

12. Żulicki, R. (2019). Pułapki myślowe data-driven. Krytyka (nie tylko) metodologiczna. Marketing i Rynek, 8, DOI: 10.13140/RG.2.2.12375.83368. 